\title{
Consonantal Phonation Rehabilitation
}

\author{
Habib M. Fardoun \\ King Abdulaziz University \\ Jeddah, Saudi Arabia \\ +966126951332 ext. 67598 \\ hfardoun@kau.edu.sa
}

\author{
Abdullah S. AL-Malaise AL- \\ Ghamdi \\ King Abdulaziz University \\ Jeddah, Saudi Arabia \\ +966 26952000 Ext. 51332 \\ aalmalaise@kau.edu.sa
}

\author{
Antonio Paules Cipres \\ European University of Madrid \\ Madrid, Spain \\ apcipres@gmail.com
}

\begin{abstract}
This paper presents an innovative system for tablets aiming at facilitating and supporting speech therapists and teachers towards the diagnosis and treatment of vocalization problems with particular interest in consonantal phonemes. As such, cloud technologies provide the appropriate place to host a platform supporting the system with the associated features due to the wider development and distribution for tablets cloud computing provides. Up to now, related resources presentation and utilisation for these vocalization difficulties are limited to pictograms and static web pages developed by speech therapists. Therefore, it is impossible to take advantage of their full potentiality for professional and practical Web and even less cloud-based environments utilisation.
\end{abstract}

\section{Categories and Subject Descriptors}

H.1.2 [Information Systems]: User/Machine Systems - Human Factors, Human Information Processing.

H.5.1 [Information Interfaces and Presentation]: Multimedia Information Systems - Audio input/output, Video.

H.5.2 [Information Interfaces and Presentation]: User Interfaces - Graphical user interfaces (GUI), Interaction styles, Screen design, User-centered design, Voice I/O.

\section{I.4.9 [Computing Methodologies]: Applications.}

J.1 [Computer Applications]: Administrative Data Processing Education.

J.3 [Computer Applications]: Life and Medical Sciences Health, Medical information systems.

\section{General Terms}

Languages

\section{Keywords}

Speech Therapist, Phonemes, Phonation, Rehabilitation, Cloud.

Permission to make digital or hard copies of all or part of this work for personal or classroom use is granted without fee provided that copies are not made or distributed for profit or commercial advantage and that copies bear this notice and the full citation on the first page. To copy otherwise, to republish, to post on servers or to redistribute to lists, requires prior specific permission and/or a fee. REHAB 2014, May 20-23, Oldenburg, Germany Copyright (C) 2014 ICST 978-1-63190-011-2

DOI 10.4108/icst.pervasivehealth.2014.255391

\section{INTRODUCTION}

According to the Real Academy of Spanish Language [1], sound is: the oral realization of a phoneme, which is constituted by pertinent and non-pertinent features. Sound is also a mental representation of a phoneme in the brain. The language sounds are innumerable, as many as the speakers and even more as many as a speaker uses them. This physic realization of the $t$ or the $r$ is what we call sound. For example, there is only one $t$ or one $r$ in the speaker's mind; however, later on, there are indeed a lot of forms to pronounce them. This ideal and unique $t$ or $r$ is what we call phoneme.

For example, if several people pronounce the word train, more or less clear differences in the pronunciation can be noticed; the $t$ would sound more or less energetic; the $r$ would vibrate more or less. Even if the same person pronounces a word in different situations there will be noticeable variations. These variations, perceptible to the ear, are much clearer when we use special equipment.

Consequently, when we classify consonants, attention is attached not only to the place where they are pronounced, but also consideration is needed on the manner they are pronounced. These two elements are known as 'the articulation's point' (the place inside of the mouth cavity where it is used) and the articulation's mode (elements involved in the pronunciation).

\section{CONSONANTAL PHONEMES CLASSIFICATION}

The sound produced by de vocal cords is a "raw" sound and does not differentiate with the animal sounds. When reaches the mouth, this "noise" is modified so to be converted into sound; this modification is what we call articulation.

Articulation is the position adopted by the mouth's organs when producing a sound. The sound articulation organs are classified in actives (lips, tongue, inferior teeth, palate) and passives (superior teeth, superior alveolus, palate) [2][3]. As for the consonantal sounds articulation, there is always a bigger or smaller barrier blocking the air from the lungs to the exterior space. Depending on the circumstances around this exit of the air, there are diverse factors need to be taken into account for their classification [4][5]:

- Articulation's point or Articulation's zone. This is the place where the organs, which participate in the sound production, make contact. It can be classified into features depending on the previous fact. 
Table 1. Articulation's point classification

\begin{tabular}{|c|c|c|}
\hline Feature & Organs & $\begin{array}{l}\text { Examples } \\
\text { (Spanish) }\end{array}$ \\
\hline Bilabial & The lips & $/ \mathbf{p} /, / \mathbf{b} /, / \mathbf{m} /$ \\
\hline Dental Lip & Inferior lip and superior teeth. & $/ \mathbf{f} /$ \\
\hline Inter dental & The tongue among the teeth. & $\mid \mathbf{z} /$ \\
\hline Dental & $\begin{array}{l}\text { The tongue behind of superior } \\
\text { teeth. }\end{array}$ & $\mathrm{r} / \mathrm{t} /, / \mathbf{d} /$ \\
\hline Alveolar & $\begin{array}{l}\text { The tongue over the superior } \\
\text { teeth's root. }\end{array}$ & $\begin{array}{l}\mathrm{r} / \mathbf{s} /, / \mathbf{l} /, / \mathbf{r} / \\
/ \mathbf{r r} /, / \mathbf{n} /\end{array}$ \\
\hline Palatal & Tongue and palate. & $\begin{array}{l}/ \mathbf{c h} /,{ }^{\prime} / \mathbf{y} / \\
/ \mathbf{l l} /, / \mathbf{n} /\end{array}$ \\
\hline Velar & Tongue and palate's veil. & $/ \mathbf{k} /, / \mathbf{g} /, / \mathbf{j} /$ \\
\hline
\end{tabular}

- Articulation's mode: This is the posture that the organs, which produce the sounds, adopt.

Table 2. Articulation's mode classification

\begin{tabular}{|l|l|l|}
\hline Feature & \multicolumn{1}{|c|}{ Organs } & \multicolumn{1}{|c|}{$\begin{array}{l}\text { Examples } \\
\text { (Spanish) }\end{array}$} \\
\hline Occlusive & Total and momentary air closure. & $\begin{array}{l}\text { p/p/,/b/,/t//,/d/, } \\
/ \mathbf{k} /, / \mathbf{g} /, / \mathbf{n} /, / \mathbf{m} /\end{array}$ \\
\hline Fricative & $\begin{array}{l}\text { Narrowing by where the air is passing } \\
\text { through. }\end{array}$ & $\mathbf{f} /, / \mathbf{z} /, / \mathbf{j} /, / \mathbf{s} /$ \\
\hline Affricate & $\begin{array}{l}\text { An occlusion is produced and after that } \\
\text { a frication. }\end{array}$ & $/ \mathbf{c h} /, / \mathbf{n} /$ \\
\hline Lateral & $\begin{array}{l}\text { The air grazes the laterals of the mouth } \\
\text { cavity while passes through. }\end{array}$ & $/ \mathbf{l} /, / \mathbf{l l} /$ \\
\hline Vibrant & $\begin{array}{l}\text { The air makes to vibrate the point of the } \\
\text { tongue when it passes through. }\end{array}$ & $/ \mathbf{r} /, / \mathbf{r r} /$ \\
\hline
\end{tabular}

- Vocal cords activity: When we produce sounds, the vocal cords may vibrate or not. If the vocal cords do not vibrate, the sounds are called deaf; when the opposite happens, and the vocal cords vibrate, the sounds are called sonorous.

Table 3. Vocal cords activity classification

\begin{tabular}{|l|l|l|}
\hline Feature & \multicolumn{1}{|c|}{ Organs } & \multicolumn{1}{c|}{ Examples (Spanish) } \\
\hline Deaf & The vocal cords don't vibrate. $/ \mathbf{p} /, / \mathbf{t} /, / \mathbf{k} /, / \mathbf{c h} /, / \mathbf{z} /, / \mathbf{s} /, / \mathbf{j} /, / \mathbf{f} /$ \\
\hline Sonorous & The vocal cords vibrate. & $\begin{array}{l}/ \mathbf{b} /, / \mathbf{z} /, / \mathbf{d} /, / \mathbf{l} /, / \mathbf{r} /, / \mathbf{r r} /, / \mathbf{m} /, \\
/ \mathbf{n} /, / \mathbf{l l} /, / \mathbf{y} /, / \mathbf{g} /\end{array}$ \\
\hline
\end{tabular}

Nasal cavity activity: When humans produce sounds, part of the air passes through the nasal cavity; these sounds are called nasals. When the air passes through the mouth cavity, these sounds are called orals.
Table 4. Nasal cavity activity classification

\begin{tabular}{|l|l|l|}
\hline Feature & \multicolumn{1}{|c|}{ Organs } & $\begin{array}{l}\text { Examples } \\
\text { (Spanish) }\end{array}$ \\
\hline Nasal & $\begin{array}{l}\text { Part of the air passes through the } \\
\text { nasal cavity. } \\
\text { Oral }\end{array}$ & \begin{tabular}{l} 
All the air passes through the mouth. $/ \mathbf{n} /, / \tilde{\mathbf{n}} /$ \\
\hline
\end{tabular} \\
\hline
\end{tabular}

Based upon this classification, the consonantal phonemes classification summary is presented in the following table.

Table 5. Consonant phonemes classification

\begin{tabular}{|c|c|c|c|c|c|c|c|c|c|c|c|c|c|c|}
\hline \multicolumn{2}{|c|}{ | } & \multicolumn{2}{|c|}{ 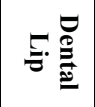 } & \multicolumn{2}{|c|}{ 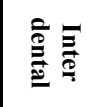 } & \multicolumn{2}{|c|}{$\begin{array}{l}\mathscr{\mathscr { E }} \\
\stackrel{\Xi}{\ddot{E}}\end{array}$} & \multicolumn{2}{|c|}{$\begin{array}{l}\frac{R}{d} \\
\frac{8}{2} \\
\frac{\mathscr{2}}{2}\end{array}$} & \multicolumn{2}{|c|}{ 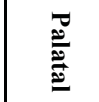 } & \multicolumn{2}{|c|}{$\frac{\overparen{a}}{\stackrel{2}{\dddot{m}}}$} & \\
\hline 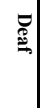 & $\mid$ & $\stackrel{\square}{\stackrel{\mathscr{B}}{\rightleftarrows}}$ & 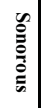 & 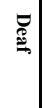 & 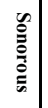 & $\stackrel{\bullet}{\stackrel{B}{\mathscr{E}}}$ & 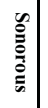 & $\stackrel{\bullet}{\stackrel{\mathscr{B}}{=}}$ & 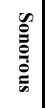 & $\stackrel{\nabla}{\mathscr{Q}}$ & 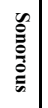 & 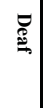 & 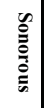 & \\
\hline $\mathbf{p}$ & b & & & & & $\mathbf{t}$ & d & & & & & $\mathbf{k}$ & $\mathbf{g}$ & Occlusive \\
\hline & & & & & & & & & & $\operatorname{ch}$ & & & & Affricate \\
\hline & & f & & $\mathbf{Z}$ & & & & $\mathbf{S}$ & & & $\mathbf{y}$ & $\mathbf{j}$ & & Fricative \\
\hline & & & & & & & & & I & & II & & & Lateral \\
\hline & & & & & & & & & $\begin{array}{l}\mathbf{r}, \\
\mathbf{r r}\end{array}$ & & & & & Vibrant \\
\hline & $\mathrm{m}$ & & & & & & & & $\mathbf{n}$ & & $\tilde{\mathbf{n}}$ & & & Nasal \\
\hline
\end{tabular}

There are mechanisms that a speech therapist performs during such problems detection related to the phonemes' vocalization and pronunciation due to the dysarthria. The target is to detect and evaluate the functionality of the organs so to validate the functionality degree following the previous attributes. These mechanisms are connected to checking and evaluating the lips positioning, teeth's positioning, tongue's movement, palate's veil or sonorous glottis. These are all parts of the human's speech system and are the most commonly described for a speech therapist so to treat and comment on treatment upon, as referred previously.

\section{OBJECTIVES}

This paper presents a cloud-based system aiming at helping speech therapists, teachers and parents in the identification, prevention, diagnosis and rehabilitation of patients with problems on pronouncing consonants. After seeing a speech therapist and attending therapy sessions with a pronunciation problems patient, the consonants for clinic motives were chosen for this study. These problems were due to serious clinic motives such as an ear infection with hearing loss so the patient recovers very slowly. In this case, a primary school teacher noticed that a student could not pronounce the consonants properly; so he suggested to his parents to go and see a speech therapist so the student can get specific phonetic exercises targeting at avoiding the delay in his learning. The patient has completely recovered; there were no delays in his 
educational process in acquiring his normal hearing functionality after only a year.

Therefore, the research target is to design and develop an application so to detect whether a school student appears to have any type of hearing problems so to start his/her treatment as soon as possible avoiding both hearing organs functionality difficulties as well as educational problems.

\section{STUDY CASE}

In this case study, a prototype is presented within four therapist's sessions. Just as a note, in one of the sessions the patient rejected to perform any of the exercises proposed by the speech therapist due to the known environment available for this task.

First, a prototype environment was designed; the system uses pictograms with added text to facilitate the speech therapist at creating words' composition so that a child can watch his/her process with his/her parents or tutor targeting at providing an initial diagnosis.

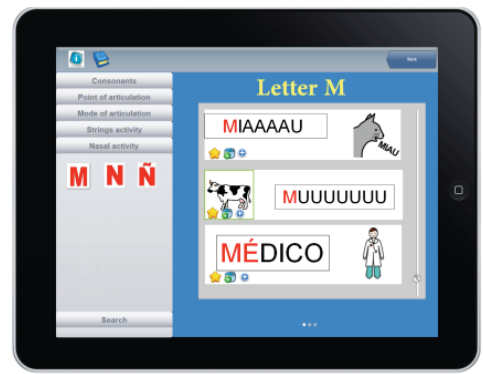

Figure 1. Phonemes histories generation screen

In Figure 1, the speech therapist compares the phonemes necessary to support diagnosis. As such, the therapist accesses a pictographic database with words selection representing the phonemes.

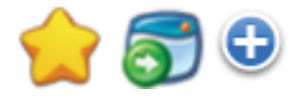

Figure 2. Application buttons

The buttons, as in Figure 2, perform the following actions:

- $\quad$ Add the information to favorites.

- $\quad$ Go directly to patient's history.

- Add minimum text required to complete the pictogram and associated information.

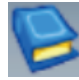

\section{Figure 3. Book button}

When the book button is pressed (as in Figure 3), the speech therapist sees an identified patient's history on the device's screen and can fill it in and complete the information needed. The usual process is that, depending on the child's age, there are minimum actions required to add words associated to images the child is able to pronounce.

In Figure 4, the speech therapist accesses to the patient's histories and pictograms on a day-to-day basis. Based upon the personalized library, the therapist may perform the necessary modifications for every diagnosis and/or treatment. Therefore, the interface provides options for 'search' and 'edit' at the top screen section, where the user can pre-visualize, add, remove or share a patient's history.

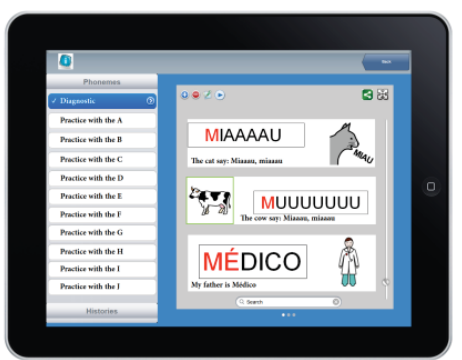

Figure 4. Generated histories collection

The "share history" button allows the speech therapist to send a patient's history to the child's parents so to support the student in performing the suggested exercises in an easier way; thus, the number of entries is increased so to support and confirm the exact diagnosis.

The teacher or parent receives the suggested exercise/s the child has to perform in his/her terminal so to support and finalize the diagnosis. These exercises can be repeated several times in many different histories targeting at detecting the phonemes the child has difficulties in pronouncing them properly. In Figure 5, the child pronounces the phonemes; the application stores the data and finally the data is sent to the server.

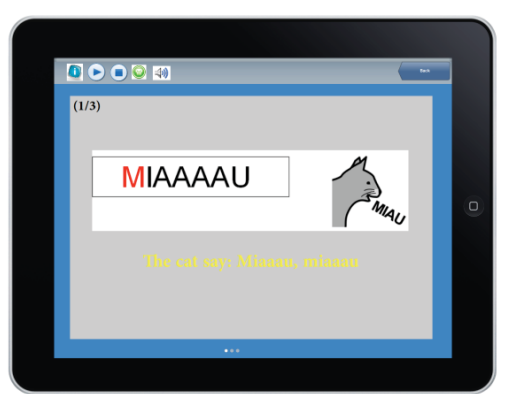

Figure 5. Diagnosis screen

The speech therapist indicates the specific steps to perform towards a complete exercise so to support the child's diagnosis. In this example, a child articulates the phoneme without the needed larynx's vibrations replacing $/ \mathrm{b} /$ by the phoneme $/ \mathrm{p} /$. The correction is as follows:

- In front of a mirror the parents suggest him/her to observe the correct position in articulating the phoneme 'b'.

- $\quad$ Perform lip massages.

- Articulate several words starting with the letter ' $b$ '.

First, the child uses the tablet to watch the ways the lips are positioned when they are moving, pronouncing words with the letter ' $b$ '. These video records are stored in the system platform. Then, the speech therapist generates specific exercises for the child as in Figure 5. 


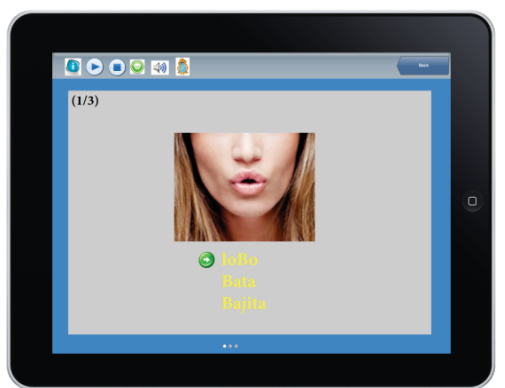

Figure 6. Lips positioning

The parent or teacher can click on the "mirror" button, so to aid the child to compare the image of his/her lips, captured by the tablet's webcam, with the ones on the video. Below, screen captures present the ways the rehabilitation exercises of the phoneme $/ \mathrm{b} /$ are represented on tables. These tables are consisted of several written words with the consonantal sound /b/. In Figure 7 , the child pronounces the words and watches both the video and his face so to improve the lips positioning during the pronunciation of the phoneme $/ \mathrm{b} /$.

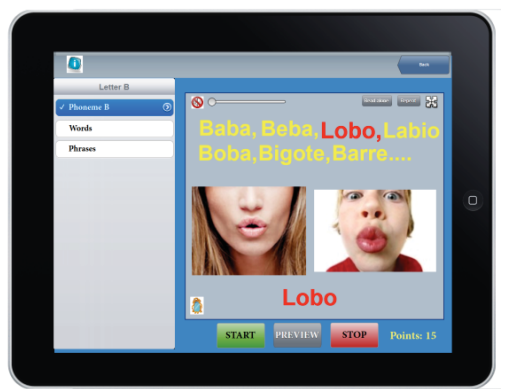

Figure 7. Phonetic exercises tables

\section{ARCHITECTURE}

This section presents the proposed system's architecture. Consideration was taken towards automating the tasks in order to recognize the phonemes, one in each diagnosis phase. This process can be conducted by the speech therapists or the system as such, and, at the same time, prepares the exercises collection in order to provide with the therapeutic sequence so to support the patient's treatment.

The speech therapist performs the phonetic rehabilitation exercises by filtering and testing. The platform also analyzes the diagnosis exercises suggested by the speech therapist or the system as such for the children to do. Thus, the therapist receives a report with the phonemes and the rehabilitation exercises processing and in result, analyses the platform selects and the child later completes on the mobile device.

\section{CONCLUSIONS}

This paper presents the initial work on the documentation of sessions so to assist speech therapists and associated support centres. This research was due to the fact that any improvement in a child's phonation process is actually based upon a rehabilitation technique. Therefore, risks exist related to this new form of understanding the speech therapy, by utilising the new generation of computer applications as an extension of a users' diagnosis and therapy necessities.

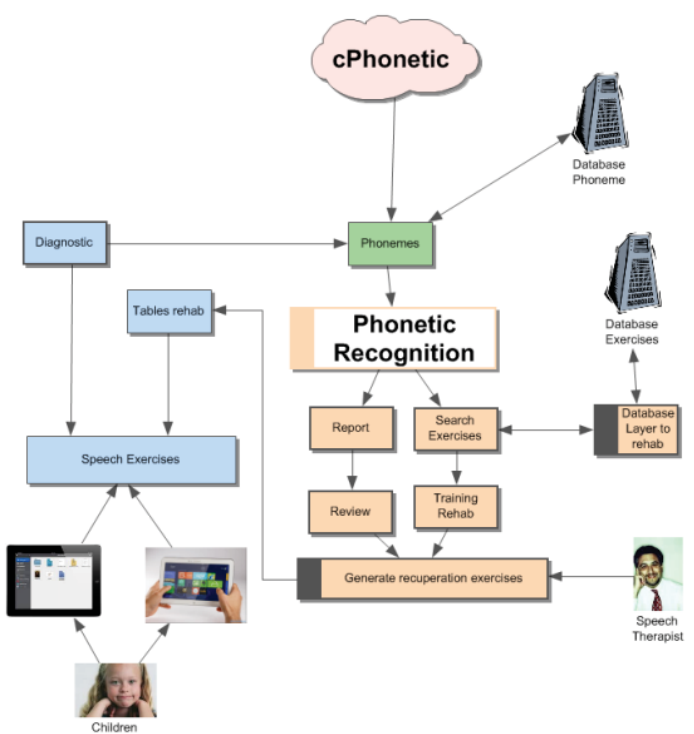

Figure 8. System Architecture

More research work is needed on children with phonation problems and the rehabilitation processes related to designing new hardware. This is due to the fact that the speech therapists need to be involved in the early stages of tools design and equipment built by them. A possible extension of this line of research may focus upon the use of phonetics and associated techniques therapists use, in order to support the foreign languages learning processes. As such, improving the students' expression capacity in a foreign language can be a major target in future research.

\section{REFERENCES}

[1] Diccionario de la Real Academia (Dictionary of the Real Academy). http://lema.rae.es/drae/?val=sonido.

[2] Antonio Valles Arandiga. Prueba de articulación de fonemas: Evaluación de la dislalia, CEPE. Ciencias de la educación preescolar y especial. ISBN: 9788478690176.

[3] Manual de Fonética Española. Eugenio Martínez Celdrán, Ana Fernández. Ed Ariel. ISBN: 9788434482722.

[4] Martínez Celdrán, E. Fonología general y española, Ed. Teide. ISBN: 9788430773442.

[5] Quilis Antonio. Tratado de fonología y fonética españolas. Gredos. ISBN: 9788424922474.

[6] Habib M. Fardoun, Abdulraham H. Altalhi, Antonio Paules Cipres, Jaime Ramírez Castillo, Sergio Albiol-Pérez.

CRehab: A Cloud-based Framework for the Management of Rehabilitation Processes. 7th International Conference on Pervasive Computing Technologies for Healthcare (PervasiveHealth), 2013. Pages: 397 - 400. E-ISBN: 978-1936968-80-0.

[7] Habib Fardoun, Francisco Montero, Víctor López Jaquero. eLearniXML: Towards a model-based approach for the development of e-Learning systems considering quality. Advances in Engineering Software. 2009. Pages: 1297-1305. DOI: http://dx.doi.org/10.1016/j.advengsoft.2009.01.019. 
[8] Habib M Fardoun, Antonio Paules Ciprés, Daniyal M Alghazzawi. CSchool: DUI for Educational System using Clouds. Proceedings of the 2nd Workshop on Distributed User Interfaces: Collaboration and Usability. In conjunction with CHI 2012. Pages: 684-695. 